EDITORIAL

\title{
Trabalho profissional do/a Assistente Social: estratégias de resistência em tempos de regressão de direito ${ }^{1}$
}

\author{
Professional work of the Social Worker: strategies of resistance in times of right regression
}

\author{
JANE CRUZ PRATES $\odot$
}

Pontifícia Universidade Católica do Rio Grande do Sul, Porto Alegre, RS, Brasil.

8003

\section{A}

formação e o trabalho profissional, um binômico que não pode ser dicotomizado, se realiza e é condicionado pelo solo histórico no qual se desenvolve, logo, para analisar os desafios que se colocam à formação e ao trabalho do/a assistente social é importante realizar uma breve retrospectiva histórica para tentar explicar o desastroso contexto presente. Esse contexto é marcado pelo avanço do conservadorismo, retrocessos em relação a direitos fundamentais da classe trabalhadora e ameaça aos espaços democráticos. Porém, no ano em que o Serviço Social brasileiro comemora 40 anos do Congresso da Virada, é necessário desocultar os processos manipulatórios e os movimentos regressivos a que estamos sujeitos, no intuito de fortalecer o seu contraponto, a análise crítica da realidade e as resistências coletivas.

Pretendo fazer isso considerando o período pós-Constituição de 1988 e os governos que se sucederam para que possamos interpretar de modo mais consistente o grave momento que vivemos hoje e os desafios que se colocam para a classe trabalhadora e para os assistentes sociais em particular.

No cotidiano, diz Lefebvre (1991), se expressa a decadência e a fecundidade, a miséria e a riqueza, a dualidade que articula em uma unidade conformismo e atividade criadora, revolucionária. Guardemos esse pensamento para retomá-lo posteriormente ao final da exposição deste artigo. Mesmo considerando a existência da contradição dialética como parte constitutiva do real, atualmente, parece predominar o desencanto e a perplexidade, afinal, vivemos um momento de crise internacional do capital cujas estratégias terminam por proteger o capital financeiro e penalizar o emprego e o consumo, com impactos significativos na seguridade social e na vida da classe trabalhadora que depende de políticas sociais para manutenção das suas condições materiais de existência. Por outro lado, a questão social não se expressa só a partir de desigualdades, mas também a partir da força e da resistência manifesta pelos sujeitos sociais e no último dia 15 de maio foi possível vivenciar esse processo e recompor as energias para efetivar a resistência coletiva na luta contra os cortes na Educação e a reforma da previdência, um dos maiores ataques contra os direitos dos trabalhadores dos últimos tempos, uma vez que rompe com a solidariedade que está na base da seguridade social prevista na Constituição Federal de 1988 e instaura a capitalização em substituição a proteção.

Ocupamos as ruas, fomos mais de 2 milhões em cerca de 222 cidades brasileiras. Participar de processos dessa ordem não é importante somente para tensionar o Executivo e o Legislativo a acolher nossas demandas, mas para que nos fortaleçamos enquanto classe. Mauro lasi (2008) diz que as greves e as paralizações são os principais espaços pedagógicos de formação da classe, espaço onde a energia coletiva nos contagia e mobiliza.

Mas a nossa história é marcada por largos períodos de colonização, escravismo, ditadura e populismo, pelo desenvolvimento de um capitalismo dependente e de um estado de bem-estar inconcluso, por uma educação tardia premida por reformas verticais que sempre atenderam interesses particularistas e não às necessidades da população. Do mesmo modo, é marcada pela inversão na constituição dos direitos, pela política do favor, da moeda de troca, do patrimonialismo e do coronelismo, que teimam em se reeditar, pela 
conformação de uma burguesia extremamente conservadora e subalterna ao grande capital internacional e por uma sociedade civil frágil, fruto de amplos períodos em que a participação lhe foi negada.

A Constituição de 1988, conformada no período de abertura democrática, após 21 anos de ditadura, embora tenha sido fruto de uma disputa de forças que reduziram a amplitude dos direitos almejados pela sociedade, obteve avanços significativos, entre os quais, a garantia da seguridade social, composta pelas políticas de saúde, assistência social e previdência social, as primeiras, não contributivas, dever do estado e direito do cidadão, e a última contributiva. Além disso foi de fundamental importância a garantia de percentuais orçamentários previstos em lei para a saúde e a educação, considerando tratarem-se de políticas estruturantes, e por fim, mas não menos importante, a gestão conjunta entre o governo, a sociedade e a instituição de conselhos paritários compostos pelo governo e pela sociedade civil para materialização do processo de cogestão.

Esses avanços exigiam a manutenção de um estado social forte, que pudesse materializar efetivamente o que se aprovara na Carta Magna.

Contudo, a década de 1990 foi marcada pela implementação das políticas de recorte neoliberal no Brasil, que tinham na minimização do estado social e nos processos de privatização a sua centralidade. Essas iniciativas, associadas à morosidade na implementação das leis complementares que viabilizavam a materialização das políticas e a implementação de instâncias paralelas criadas pelo governo, que se sobrepunham a gestão conselhista, como o Comunidade Solidária, a destituindo mesmo antes que se consolidasse, foram óbices encontrados durante o governo Fernando Henrique Cardoso para dar materialidade aos avanços constitucionais.

Mesmo assim, nos anos 1990 tivemos a implantação do Sistema Único de Saúde (SUS), do Estatuto da Criança e do Adolescente (ECA) e da Lei Orgânica de Assistência Social (LOAS), com a participação ativa dos assistentes sociais nesses processos de suma importância para a atenção e a proteção social da sociedade brasileira.

A vitória de Lula, freia em parte o ímpeto neoliberal intenso que marcou o início da década de 1990, mas infelizmente não de modo radical. Embora de caráter popular, o novo governo tinha uma constituição híbrida, composta não só por partidos de esquerda, mas também por partidos de centro e de direita, lembremos, que o próprio vice-presidente de Lula, era José de Alencar, do Partido Liberal, e que o ministério de Lula, além do Partido dos Trabalhadores (PT) era constituído por ministros do PPS, PDT, PMDB PL e PSB, além de Meirelles, do PSDB, à frente do Banco Central.

Logo, é importante termos claro que nunca tivemos no Brasil uma coligação unicamente de esquerda, mas composições com representantes da burguesia e dos oligopólios que historicamente comandaram o País, ocupando cargos-chave e disputando no centro de governo ações opostas em termos políticos. Portanto, embora Lula e Dilma tenham implementado políticas importantes de interesse popular, elas sempre atenderam ao mesmo tempo aos interesses do capital, ou não teriam sido implementadas, logo, o histórico processo de conciliação foi mantido.

Contudo, não há como negar que, embora contraditórias, as políticas implementadas por Lula e Dilma incidiram de alguma forma sobre as condições materiais de existência da população, em que pesem nossas próprias críticas. Somente na área da Educação, por exemplo, foram criadas 18 Universidades Federais, enquanto nenhuma foi criada no governo de Fernando Henrique Cardoso, o Reestruturação e Expansão das Universidades Federais (REUNI) forneceu recursos importantes para a interiorização da universidade pública, permitindo que filhos de trabalhadores não tivessem que se deslocar para grandes centros para estudar. $O$ Programa Universidade para Todos (PROUNI) distribuiu 1,2 milhões de bolsas e o Financiamento Estudantil (FIES) atendeu a 1,3 milhões de pessoas com financiamento. Sem dúvida, essas medidas de financeirização da Educação são bastante controversas, mas diante do histórico crescimento da universidade privada no Brasil, havia a necessidade de uma transição para que os estudantes não tivessem o acesso impedido, por longo espaço de tempo, até que fossem criadas as condições objetivas para que essa oferta pudesse ser coberta pela universidade pública. Esse movimento de mão dupla precisava ser feito e, é bem verdade que as orientações do Banco Mundial e Fundo Monetário Internacional (FMI) indicavam a necessidade de formar grandes contingentes de mão de obra trabalhadora especializada. Logo, o mercado desejava esse processo, 
cuja multiplicação tem no Ensino a Distância (EAD) seu expoente máximo, modalidade esta, aprovada no governo Lula. Por outro lado, há de se reconhecer que embora insuficientes, houve avanços nas iniciativas relativas à garantia de direitos para as mulheres, para as pessoas com deficiência, os idosos, as juventudes, a população negra, as populações em situação de rua e as populações LGBT.

Em 2008, com a crise internacional do capital que se agrava, com repercussões desastrosas na área do emprego e da seguridade social nos mais diversos países do mundo, o Brasil implanta as políticas anticíclicas ou neodesenvolvimentistas para enfrentar a crise, fazendo com que seus impactos fossem protelados no País, por cerca de cinco anos, o que com a queda internacional do preço das commodities não foi mais possível manter. A última eleição de Dilma, uma disputa acirrada, ocorre em meio ao recrudescimento da crise no Brasil e descontentamento de parte da população com a situação recessiva, por sua vez, a direita que perdera as eleições não se conforma e passa a articular o golpe, com o apoio da mídia e do então vice-presidente Michel Temer.

Temer era ainda vice-presidente de Dilma quando lançou o Plano Ponte para o Futuro, que se comprometia a atender aos anseios neoliberais de flexibilização de direitos e espaços democráticos, plano esse articulado com as federações de indústria estaduais. Não esperavam, contudo, que o golpe fizesse surgir uma liderança como a de Bolsonaro, de ultradireita, mesmo assim, no curto e nefasto governo Temer, tivemos importantes perdas, como a Lei n.o 95/2016 de reajuste fiscal ou Lei do congelamento e a Reforma Trabalhista, que mexeu em direitos fundamentais como férias, jornada de trabalho, remuneração e plano de carreira.

É importante, porém, destacar o importante papel da mídia nesse processo, formando opinião, realizando mobilizações, incentivando o antipetismo como forma de instigar a população contra a esquerda de um modo geral. O PT foi responsabilizado por toda e qualquer mazela vivida pela sociedade brasileira, onde se incluía a crise financeira e a corrupção. Foi fundamental a participação da mídia na disseminação dessas ideias para a efetivação do golpe. $E$ as ruas foram tomadas por conservadores, que não só reclamavam da corrupção, mas explicitavam seu ódio ao PT e a toda forma de movimentos sociais organizados; rechaçavam pensadores como Paulo Freire, que sempre apregoou a participação das massas; rechaçavam partidos e sindicatos, que mobilizavam grandes massas de trabalhadores; e enalteciam a ditadura, a Lava Jato e o nacionalismo.

Manifestações desse tipo, podem ser comparadas às chamadas revoluções coloridas, inspiradas na produção de Gene Sharp, cientista político estadunidense, fundador da Albert Einstein Institution, cujo livro intitulado Da ditadura à democracia foi traduzido para mais de 25 idiomas e distribuído pelo mundo por ONGs como a Freedom House, MacCaim Foundation, Clinton Foundation, entre outras, financiadas por bilionários como George Soros e os irmãos Koch. Constituído como uma espécie de manual que orienta as intervenções não violentas, tem fundamentado ações que acabam por contribuir com a desestabilização de governos cuja direção se contraponha à concepção de democracia norte americana e/ou a de Bruxelas. É parte do trabalho das ONGs formar lideranças jovens que se identifiquem com esses projetos sob o discurso de formar para "a democracia" e para "os direitos humanos". Essa iniciativa vem, de longa data, influenciando importantes movimentos, como a primavera árabe e outros que eclodiram na China, na Ucrânia, na Geórgia, como as chamadas revoluções rosa, das tulipas e revolução laranja. Movimentos similares ocorreram, em 2011, no Oriente Médio e Norte da África, em países como Egito, Tunísia, Líbia, Argélia, lemêm, Bahaim e Síria (MARTINEZ, 2016).

Não há dúvidas que muitos são os determinantes que conformam esses movimentos, não sendo possível reduzi-los a um único elemento, mas certamente o trabalho de lideranças tem um papel chave na sua mobilização e disseminação. No caso brasileiro, a formação de lideranças de direita foram fundamentais em determinados contextos históricos, como o golpe de 1964, para propagar os ideais dos grupos que detinham o poder, como bem destaca Dreifuss (1981) ao aportar reflexões sobre o papel das elites orgânicas no Brasil que, a exemplo de suas organizações-irmãs americanas, exerceram importante papel na luta política e ideológica para apoiar a modernização-conservadora, a internacionalização da economia e a contenção dos movimentos populares. O autor apresenta, como exemplos desses grupos de ação, o Instituto de Pesquisas e Estudos Sociais (IPES) e o Instituto Brasileiro de Ação Democrática (IBAD). Conforme o autor, essas 
organizações representavam o pensamento do empresariado brasileiro, mas para legitimarem-se e consolidar a sua hegemonia mantinham-se articulados com figuras de destaque do Parlamento, profissionais liberais, diplomatas; e em seus órgãos operacionais com militares, estudantes, intelectuais, ativistas comunitários e segmentos do movimento sindical. Uma de suas funções principais era a desestabilização dos governos constituídos. Para tanto, mantinham cursos especiais a fim de formarem lideranças comunitárias, estudantes e dirigentes sindicais; realizavam ações cívicas e comunitárias com o objetivo de "frear a politização", conter as demandas da esquerda, capitalizando os anseios populares. Realizavam ações de penetração política e pressão, através da mídia, da burocracia do Estado e do uso do tráfico de influências (PRATES, 1995).

Não há dúvidas que é de fundamental importância ouvir as ruas, mas sem organização e politização, as massas são facilmente utilizadas e manipuladas por processos de alienação que distorcem fatos, veiculam alguns e obscurecem outros, atendendo a interesses de determinados grupos, muitas vezes apoiados pela mídia com eles comprometida, veiculando interesses particularistas travestidos de lutas por direitos, desenvolvimento e ordem, mas que, na verdade, trazem no seu bojo prejuízos substantivos aos interesses públicos, como é o caso da reforma da Previdência no Brasil, que tem sido apresentada de forma distorcida como a solução para todos os problemas fiscais do País.

Esses movimentos e grupos, mencionados anteriormente, tinham como bandeira a crítica, a ausência de liberdade de expressão, a corrupção, os nepotismos e as supostas fraudes eleitorais. Essas, sem dúvidas eram demandas justas, mas utilizadas para fins escusos, encabeçadas por jovens ciberativistas, manipulados por interesses imperialistas, pois quando a sua ação desestabilizadora termina, entram em cena os oportunistas interessados em ocupar o espaço vazio.

A ditadura, que teve início a partir do golpe de 1964, também obteve o apoio da burguesia e da mídia, que posteriormente viram os seus interesses corroídos pelos monstros que ajudaram a criar e que se voltaram contra os seus próprios interesses.

O governo Bolsonaro, assumidamente de direita, vem acompanhado da eleição de conservadores de extrema direita no Parlamento e no Congresso, sem uma base partidária sólida, elege-se sem propostas claras, apenas comprometendo-se a combater a corrupção, vale-se das redes sociais como principal espaço de campanha, sem debates públicos ou explicitação de compromissos com a grande massa que o elegeu.

Embora ainda bastante recente, com pouco mais de 100 dias, esse governo que retoma o projeto, cuja radicalidade foi interrompida nos anos 1990 , tem se caracterizado pela instabilidade de narrativas, com muita frequência afirmações e decisões que são negadas e revistas, explicitando a falta de articulação interna do próprio governo, a falta de uma base aliada e a falta de planejamento. Esse governo, fruto da articulação entre o fundamentalismo, o conservadorismo e o neoliberalismo radical, tem como meta a minimização total do estado social, a privatização em larga escala e a entrega do patrimônio nacional ao capital estrangeiro, em que pese o seu discurso nacionalista. É parte de seu projeto a flexibilização máxima do trabalho, o desmonte de instâncias organizativas, de direitos sociais, bem como a transformação das políticas públicas em novos nichos de mercado, em especial a Educação e a Saúde, que já vêm sofrendo processos de privatização. Do mesmo modo, ficam evidenciadas a desvalorização da Ciência e do conhecimento, das instituições públicas, em especial da universidade, a criminalização dos servidores públicos, responsabilizados pelo ônus da dívida, de movimentos sociais e da liberdade de pensamento. O veiculado combate ao "marxismo cultural" e ao "esquerdismo" na universidade e a desvalorização da área das humanidades tem feito parte dos discursos do anterior e do atual ministro da Educação, ambos inspirados em Olavo de Carvalho.

Restaria muito ainda a abordar, em relação ao descaso para com a preservação da natureza, o envenenamento por agrotóxicos a que estamos sendo expostos. Afinal, mais de 30 novos agrotóxicos foram liberados no Brasil, alguns há muito proibidos em outros países, porque considerados nocivos à saúde. $O$ descaso com as terras e a população indígena; a militarização do governo; a liberação do porte de armas e da caça; a ausência de providências mais rígidas em relação às barragens, depois dos terríveis desastres de Mariana e Brumadinho. Soma-se à lista o descaso com a violência inaceitável do exército contra civis, como a morte do músico e do ambulante, no Rio de Janeiro, com 80 tiros; os absurdos veiculados em relação aos direitos humanos; a negação da diversidade humana; a imposição de padrões familiares, religiosos, de pensamento, o ataque às liberdades democráticas. 
Mas, é importante direcionar nossa atenção para refletir um pouco sobre o impacto para o Serviço Social de todo esse processo avassalador, cientes dos desafios que temos de enfrentar e que não são poucos.

Quero apenas lembrar que nos anos 1990, quando as políticas de recorte neoliberal tomavam forma no Brasil, em oposição ao ideário da Constituição, o Serviço Social articulava-se na luta pelo ECA, pelo SUS e pela LOAS, aprovamos o nosso novo código de Ética, a nova Lei de Regulamentação da Profissão e as Diretrizes da Associação Brasileira de Pesquisa em Serviço Social (ABEPSS), logo, crescemos na adversidade.

Não há dúvidas de que uma profissão fundamentada no marxismo, cuja direção social se pauta na defesa de novas formas de sociabilidade, na defesa do direito à diversidade e na participação popular, que luta pela qualidade e universalidade das políticas públicas, do acesso às riquezas socialmente produzidas para o conjunto da população, pelas liberdades democráticas e cuja grande maioria de seus trabalhadores são mulheres terá um solo histórico desfavorável à materialização de seu trabalho profissional.

Sem dúvida, nosso espaço junto às políticas sociais será bem mais restrito, em razão do desmonte e da focalização em curso, pela redução de recursos humanos em razão da suspensão de concursos públicos já anunciada pelo atual governo, o que resultará na ampliação do trabalho precário, que atinge não só ao assistente social, mas ao conjunto dos trabalhadores. Porém, é bom lembrar que as políticas de saúde e assistência social empregam aproximadamente $90 \%$ dos assistentes sociais no Brasil. Ademais, a tendência de que nos seja demandado o controle e a seleção da pobreza é uma realidade bastante provável, uma vez que as políticas tendem a ser focalizadas. Nossas pesquisas também devem sofrer cortes de recursos, porque são consideradas irrelevantes e com direções que não interessam ao pensamento dominante. Nossos processos de formação tendem à precarização, ao aligeiramento, à tecnificação em razão da inserção verticalizada do pensamento dominante na universidade, do desmonte da universidade pública e da impossibilidade de escolha dos dirigentes de forma democrática, já anunciada pelo atual governo, a exemplo da destituição dos conselhos universitários, além da redução de bolsas de estudo e de apoio para a permanência do estudante na universidade.

Os recursos para as atividades de extensão também tendem a ser reduzidos, inviabilizando iniciativas de articulação e trabalho com populações periféricas, que demandam recursos para deslocamento e para a efetivação de ações além dos muros universitários, de extrema relevância, especialmente onde os deslocamentos são intensos, como nas universidades do interior. Por outro lado, cresce vertiginosamente o conservadorismo na sociedade brasileira, fruto de uma história que mantém velados o machismo, o racismo, a misoginia, a xenofobia e, no próprio seio da profissão, verificamos os movimentos revisionistas que reeditam um trabalho subjetivista, fragmentado e conservador, como a reedição do Serviço Social Clínico ou as fatídicas 23 teses, que apregoam o retorno do Serviço Social tradicional, já superado pela categoria, além do avanço indiscriminado do EAD, em condições ainda mais precárias.

Como falar de amor e de luta diante de tantos óbices, diante de tantos desmontes e adversidades? Quero retomar o pensamento de Lefebvre que ressalta a contradição dialética, os opostos em luta, como negação inclusiva, que também conforma o cotidiano, espaço no qual materializamos nosso trabalho e nossa vida. Diz Lefebvre (1991), que no cotidiano, se expressa a decadência e a fecundidade, a miséria e a riqueza, a dualidade que articula em uma unidade, o conformismo e a atividade criadora, revolucionária. E, inspirada por esse autor, reiterar que o Serviço Social brasileiro constituiu o Movimento de Intenção de Ruptura, em plena ditadura para opor-se ao Serviço Social conservador e, nos anos 1990, durante o avanço mais agudo do neoliberalismo, crescemos como profissão e avançamos na materialização de nosso Projeto Ético Político (PEP), que nos dá uma direção social coletiva sólida, portanto não vamos vacilar nesse momento adverso, mas reagir buscando alianças com outras categorias que dialoguem com nosso projeto, fortalecendo nossas instancias organizativas, com nosso apoio e participação, porque a resistência precisa ser coletiva e não solitária. Na mesma direção, precisamos instigar formas de fortalecer a nossa consciência de classe, pois antes de sermos uma categoria profissional, somos uma classe trabalhadora; e, retomarmos a nossa vinculação histórica com as bases organizativas e populares, nos conselhos, nas redes, nas comunidades, nos sindicatos, nos partidos e nos movimentos sociais.

No presente volume a Revista Textos \& Contextos (Porto Alegre) apresenta artigos advindos de pesquisadores vinculados a universidades dos estados do Pará, Santa Catarina, Rio Grande do Norte, Rio 
Grande do Sul, Pernambuco, Ceará, Minas Gerias, São Paulo, Espírito Santo e Rio de Janeiro. Na abertura, apresenta, em língua portuguesa e inglesa, o artigo do Prof. Jaime Hillesheim, da Universidade Federal de Santa Catarina, intitulado "Conflitos de classes, defesa de direitos e Serviço Social" que compõe o Eixo 1 - Serviço Social, Educação e luta de classes. O mesmo eixo é ainda composto por mais três artigos que versam respectivamente sobre projeto ético político de Serviço Social e a construção de uma educação classista, um artigo apresentado em língua espanhola, "La internacionalización e integración regional de la Educación Superior cien años después de la Reforma Universitaria de Córdoba de 1918" e, por fim, encerrando o primeiro eixo, "O enfrentamento ao conservadorismo no Serviço Social a partir das campanhas do CFESS/ CRESS". O Eixo 2 intitulado Seguridade Social e Políticas Públicas é composto por cinco artigos, o primeiro versa sobre a reforma da previdência e intitula-se "Nova Previdência: o austericídio neoliberal sob a ótica da teoria marxista da dependência". O segundo, que conforma o eixo 2, é "A construção do direito à saúde e do SUS no cenário neoliberal e a contribuição do Serviço Social". Dando prosseguimento, apresenta-se o artigo "Financiamento da Política de Assistência Social: avanços e perspectivas" e, ainda sobre o tema da Política de Assistência Social, o artigo seguinte versa sobre "A relação de cooperação (in)existente na Assistência Social: apontamentos sobre o federalismo brasileiro". Finalizando o eixo 2, apresentamos o texto "O lugar das juventudes nas produções científicas da Estratégia saúde da família: uma revisão sistemática de literatura".

O Eixo 3 - Crise, desigualdades e violência é composto por cinco artigos, sendo que o primeiro é intitulado "Marx e a pobreza ou a influência do aumento do capital para a classe trabalhadora". O segundo texto, versa sobre mulheres em situação de rua e foi intitulado "Maria, Maria: concepções sobre ser mulher em situação de rua". O terceiro artigo versa sobre "Violências e acidentes contra idoso assistidos no atendimento pré-hospitalar no Espírito Santo, Brasil" e, logo a seguir, apresenta-se o artigo "As condições das classes trabalhadoras nas circunstâncias da crise e restauração no Brasil atual" Por fim, o artigo que fecha esse eixo aborda "Os riscos e a prevenção para homicídios intrafamiliares no Amazonas/Brasil".

No último eixo da revista, Eixo 4 - Relatos de experiência apresentamos o artigo intitulado "Relatos de experiência: impasses e reflexões sobre a proteção a testemunhas no Brasil".

Espero que as produções, investigações e reflexões contidas em mais esse número da Textos \& Contextos (Porto Alegre) possam instigar novas reflexões e inspirar alternativas de resistência em tempos tão sombrios.

Desejo a todos e a todas uma boa leitura!

A Editora

Outono de 2019

\section{Referências}

DREIFUSS, René. 1964: A conquista do Estado (ação política, poder e golpe de classe). Rio de Janeiro: Vozes, 1981.

IASI, Mauro. Ensaios sobre consciência e emancipação. São Paulo: Expressão Popular, 2008.

LEFEBVRE, H. Lógica Formal/Lógica Dialética. 3. ed. Rio de Janeiro: Civilização Brasileira, 1982.

MARTINEZ, M. Lopes. La resistencia civil examinada: de Thoureau a Chenoveth. Revista Latinoamericana, Santiago, v. 15, n. 43, p. 41-65, 2016. https://doi.org/10.4067/S0718-65682016000100003

PRATES, Jane Cruz. Gestão estratégica de instituições sociais: O método marxiano como mediação do projeto político. Dissertação (Mestrado) - PPGSS/PUCRS, Porto Alegre, 1995.

\section{Nota}

\footnotetext{
${ }^{1}$ O presente artigo decorre de exposições realizadas pela autora em Manaus, na Universidade Federal do Amazonas (UFAM), em abril de 2019, durante uma missão PROCAD (apoio Capes), e em Porto Alegre, em maio de 2019, no XIII Encontro Gaúcho de Assistentes Sociais (EGAS).
} 
Recebido em: 10/4/2019.

Aprovado em: 12/4/2019.

Publicado em: 10/10/2019.

\section{Correspondência para:}

Jane Cruz Prates

Pontifícia Universidade Católica do Rio Grande do Sul

Escola de Humanidades

Av. Ipiranga, 6681, prédio 8

90619-900, Porto Alegre, RS, Brasil

\section{Autora:}

JANE CRUZ PRATES

Doutora em Serviço Social pelo Programa de Pós-Graduação em Serviço Social (PPGSS/PUCRS).

Professora e Coordenadora do Programa de Pós-Graduação em Serviço Social da (PPGSS/PUCRS) e

Editora da Revista Textos \& Contextos (Porto Alegre).

Orcid: https://orcid.org/0000-0003-0539-3600

E-mail: jprates@pucrs.br 